\title{
Ligeiras notas sobre alguns casos de escarlatina tratados pelo soro anti-escarlatinoso
}

\author{
Trabalho apresentado á Sociedade de Medicina \\ e Cirurgia de Santos pelo dr. Benedicto Mendes \\ de Castro, do Serviço Sanitario de São Paulo.
}

TENDO-SE verificado uma epidemia de escarlatina em uma cidade do interior do Estado, offereceu-se-nos ensejo de pôr em uso o soro anti-escarlatinoso preparado pelo Dr. S. Calazans, do Instituto de Butantan, em São Paulo. longe.

Aliás, o emprego do soro no tratamento da escarlatina vem de

Essa idéa fôra considerada impraticavel por Von Pirquet não só pela difficuldade de sua obtenção em quantidade sufficiente como pela sua inefficacia segundo julgava então.

A applicação de sôro de convalescente foi feita pela $1 .^{a}$ vez por Von Leyden.

Desde então, foi a escarlatina tratada pela sorotherapia por methodos diversos, por varios auctores, Reiss e Hertz, Koch, Zungher, Mironesco, Bode, Weaver, Sow, e Fairban, e outros.

Si Holt considerava o uso deste sôro como dando optimos resultados, já $\mathrm{H}$. Place punha suas duvidas quanto ás reaçõos secundarias, acceitando, porém, determinados casos, promptas melhoras.

A conclusões positivas chegou, entretanto o casal Dick que, após estudos, declarou o sôro anti-escarlatinoso concentrado como tendo, na pratica, valor therapeutico.

A identicos resultados chegou Robb, na Inglaterra com a applicação do sôro preparado por Dockey.

Experiencias realisadas em Stockolmo deram em resultado o seguinte: - em 234 casos graves de escarlatina tratados pelo sôro, de Setembro de 916 a Agosto 917, houve uma morte em 24 casos, ou seja $17,79 \%$, ao passo que em 91 casos de gravidade egual em que não foi feita a applicação do sôro, houve 64 mortes, ou seja $70,3 \%$.

Entre nós o sôro de convalescentes de escarlatina tem sido applicado, com bons resultados, pelo professor Pinheiro Cintra. 
Mais recentemente, a optima these do Dr. Peixoto Sobrinho “"Contribuição para o estudo da sorotherapia especifica da escarlatina" sobre a applicação do sôro, nos traz a confirmação dos seus resultados nas seguintes conclusões:

- o exanthema desapparece rapidamente;

- a angina apresenta accentuada melhora;

- não ha nephrite post-escarlatinosa;

- o sôro deve ser applicado em altas doses e o mais precocemente possivel.

Cantacuzène, na Revista "Annales des Laboratoires Clin" MarçoAbril 927 diz: "o tratamento pelo sôro dos convalescentes tem sido empregado em grande escala, com successo"

Feitas essas considerações, passemos em revista os nossos casos de escarlatina tratados pelo sôro, na epidemia alludida, de Dezembro de 1926 a Março de 1927.

1. a OBSERVAÇÃo - J. M. - 10 annos - brasileiro, branco. Já teve coqueluche, não tendo tido sarampo.

Apresentou os primeiros symptomas no dia 5 de Dezembro. Nesse dia verificámos estarem as amygdalas inflammadas, sendo a temperatura de $38^{\circ}, 8$. No dia seguinte (6) appareceu o erythema generalisado por todo o corpo, a febre continuou, bem como a angina. No dia 7, não houve alteração no seu estado.

No dia $8,4^{\circ}$ dia da molestia, os symptomas continuam os mesmos. Nesse dia fizemos applicação de $15 \mathrm{cc}$ de sôro anti-escarlatinoso na região glutea, ás 16 horas. A' noite a temperatura subiu a $39^{\circ}$. No dia 9 , a temperatura era de $38^{\circ}, 8$. A angina porem, não se alterou. No dia 10 a temperatura era de $37^{\circ} 8$; a angina melhorou. No dia 11 a temperatura era normal e a angina desappareceu completamente. Começou então a descamação que se prolongou até o dia 2 de Janeiro de 1927.

2. ${ }^{a}$ observaçĩo - W. S. R. - 11 mezes, branco, brasileiro. Já teve coqueluche não teve sarampo. Apresentou em 18 de Dezembro os seguintes symptomas: febre alta, erythema generalisado, pelo que seus paes procuraram o medico. Applicamos $15 \mathrm{cc}$ de sôro anti-escarlatinoso no dia 21 , neste doente, á pedido do medico assistente.

Nessa occasião, $4 .^{\circ}$ dia da molestia, a temperatura era de $38^{\circ}$, o erythema generalisado, a lingua escarlate e as amygdalas ligeiramente inflammadas; 12 horas depois a temperatura era normal; o erythema começou a desapparecer, assim como a inflammação das amygdalas. Essa melhora se accentuou 24 horas depois, tendo o medico assistente dado alta. Houve pequena descamação limitada sómente ás pernas, durante dois dias.

3. a OBSERVAÇÃo - M. J. V. - 5 annos, brasileira, branca; não teve sarampo. Apresentou os primeiros symptomas no dia 23 de 
Dezembro, tendo logo febre alta, pelo que seus paes procuraram o medico.

A pedido do medico assistente, fizemos injecção na região glutea, de $15 \mathrm{cc}$. de sôro anti-escarlatinoso no doente. $\mathrm{Na}$ occasião da injecção ( 25 de Dezembro) o erythema era generalisado em todo o corpo, a lingua completamente escarlate e as amygdalas inflammadas. A temperatura era, nessa occasião, de $38^{\circ}, 9$. Era o $3 .^{\circ}$ dia da molestia. No dia 26, a temperatura desceu á normal; a lingua já era menos escarlate, assim como as amygdalas estavam menos irritadas e o erythema menos intenso. No dia 27 todos os symptomas haviam desapparecido completamente. A descamação foi muito pouco pronunciada e prolongou-se por mais alguns dias.

4. ${ }^{a}$ OBSERVAÇão - M. V. - 20 mezes, branco, brasileiro. Não teve sarampo nem coqueluche. Apresentou os primeiros symptomas no dia 7 de Janeiro: vomitos e febre alta. No dia 8, a temperatura era de $39^{\circ}, 8$ o erythma generalisado e a angina intensa. Fizemos immediatamente applicação de $20 \mathrm{cc}$. de sôro anti-escarlatinoso.

No dia 9 , a temperatura era de $38^{\circ}, 7$ e no dia 10 , baixou á normal tendo desapparecido todos os symptomas. A descamação foi pouco intensa e observada sómente nas virilhas.

5. a observação - M. de L. - 10 mezes, branca, brasileira. Não teve sarampo nem coqueluche. Manifestaram-se-lhe os primeiros symptomas no dia 9 de Janeiro de 1927 Consistiam esses em febre de $38^{\circ}, 7$, erythema generalisado, amygdalas inflammadas. Fizémos applicação de $10 \mathrm{cc}$. de sôro anti-escarlatinoso na região glutea do doente. No dia 10 a temperatura era de $38^{\circ}$ No dia 11 a temperatura era normal, tendo desapparecido todos os outros symptomas. Não foi observada descamação.

6. ${ }^{a}$ OBSERVAÇÃo - R. de S. - 4 annos, branco, brasileirro. Já teve coqueluche; não teve sarampo. Apresentou os primeiros symptomas no dia 24 de Janeiro. A 26 de Janeiro os symptomas eram os seguintes: temperatura de $39^{\circ}, 5$ erythema generalisado, amygdalas inflammadas, lingua escarlate; fizemos-lhe então applicação de $20 \mathrm{cc}$. de sôro anti-escarlatinoso.

No dia 27 , a temperatura era de $38^{\circ}, 6$ ás 9 horas; ás 16 horas, porém, subtia a $39^{\circ}, 5$. Fizemos injecção de mais $20 \mathrm{cc}$. de sôro. No dia 28 a temperatura baixava a $38^{\circ}$ ás 9 horas e a $37^{\circ}, 7$ ás 16 horas. Havia retenção de urina e fézes. No dia 30 foi verificada a temperatura de $37^{\circ}, 2$; o doente urinou com abundancia. No dia 31 , a temperatura subiu a $38^{\circ}, 6$; determinamos. a applicação de um clister, cujo resultado foi a expulsão de numerosos ascaris lumbricoides.

No dia $1 .^{\circ}$ de Fevereiro, nova expulsão de ascaris, temperatura normal, tendo desapparecido todos os symptomas da molestia.

$\mathrm{O}$ doente entrou em convalescença, apresentando descamação generalisada que se prolongou até 25 de Fevereiro. 
7 a obSERVAÇÃo - J. M. - 3 annos, branco, brasileiro. Já teve coqueluche; não teve sarampo.

Apresentou os primeiros symptomas em 27 de Janeiro. No dia 28, quando o examinámos, a temperatura era de $38^{\circ}, 5$. Apresentava erythema generalisado, lingua escarlate e saburrosa, ligeira amygdalite. Fizémos-lhe injecção de $20 \mathrm{cc}$. de sôro anti-escárlatinoso. No dia 29 , ás 9 horas a temperatura era de $37^{\circ}, 2$; ás 16 horas $38^{\circ}, 6$. Fizémos, então, nova injecção de $20 \mathrm{cc}$. de sôro anti-escarlatinoso.

No dia 30 a temperatura accusou $38^{\circ}, 5$, o erythema desappareceu. No dia 31 verificámos a temperatura de $38^{\circ}, 5$ ás 9 horas da manhã e de $39^{\circ}, 8$ ás 16 horas.

Uma fórte angina se declarára, então. Nos dias 1,2 e 3 de Fevereiro continuou a angina intensa, sendo improficuos os meios empregados para combatel-a. A temperatura oscillava entre $39^{\circ}, 5$ a $40^{\circ}$.

No dia 3 falleceu o doentinho com symptomas evidentes de nephrite aguda.

8. ${ }^{a}$ observaÃço - M. A. G. M. - 20 mezes, brasileira, branca. Apresentou os primeiros symptomas de escarlatina em 2 de Fevereiro de 1927.

No dia 8, 6 dias após, á pedido do medico assistente, fizémos a injecção de $20 \mathrm{cc}$. de sôro anti-escarlatinoso. A temperatura era de $39^{\circ}, 1$. Angina intensa, e, em formação, um abcesso na face direita do pescoço. No dia 9 a temperatura continuou a mesma; fizémos injecção de mais $20 \mathrm{cc}$. de sôro anti-escarlatinoso. A temperatura, bem como os demais phenomenos, continuaram pelos dias seguintes.

No dia 14, o abcesso foi aberto e no dia 15 a doente começou a apresentar symptomas de nephrite aguda, tendo fallecido a 16 .

9. a observação - N. A. S. - 14 annos, branca, brasileira. Apresentou os primeiros symptomas no dia 10 de Fevereiro de 1927.

No dia 12, quando fomos chamados, a temperatura era de $40^{\circ}, 3$, a angina intensa, assim como o erythema generalisado por todo o corpo. Fizémos nesse dia, a injecção de $20 \mathrm{cc}$. de sôro anti- escarlatinoso.

No dia 13 verificámos uma temperatura de $39^{\circ}, 5$, no dia 14 de $39^{\circ}, 5$, no dia 15 de $37^{\circ}, 8$. A angina melhorou só no dia 15 . O eryhema desappareceu completamente no dia 14, começando a descamação. A descamação do corpo foi rapida, ao passo que a da mão e do pé se prolongou até o dia 20 de Março. Apresentou, a 18 de Fevereiro, otite, que desappareceu com medicação apropriada.

10. a obSERVAÇÃo - N. I. - 3 annos, brasileiro, branco. Já teve coqueluche.

Apresentou os primeiros symptomas no dia 19 de Fevereiro de 1927 No dia 21 quando fomos chamados, fizémos injecção de $20 \mathrm{cc}$. de sôro anti-escarlatinoso. A temperatura, nesse dia, accusava $38^{\circ}, 2$, 
no dia $2237^{\circ}, 2$ e assim se conservou até o dia 26 . No dia 21 as amygdalas apresentavam reacção franca, e erythema generalisado e a urina turva. No dia 22, notámos um infartamento ganglionar de ambos os lados do pescoço. Aos poucos, todos os phenomenos foram desapparecendo até o completo restabelecimento. A descamação da mão e do pé prolongou-se até o dia 26 de Março, ao passo que a do corpo foi muito pouco pronunciada.

Apresentou ligeira nephrite aguda durante um dia, que desappareceu com regimen adequado.

11. a OBSERVAÇÃo - E. M. - 7 annos, brasileira, branca. Já teve sarampo e coqueluche.

No dia 2 de Março, em que fizémos injecção de $20 \mathrm{cc}$. de sôro anti-escarlatinoso, as amygdalas estavam inflammadas e o erythema generalisado.

A temperatura accusava $37^{\circ}, 6 ; 24$ horas depois a temperatura era de $36^{\circ} 6$, a angina menos intensa assim como o erythema.

Esses symptomas foram desapparecendo, restabelecendo-se a doente, em pouco tempo.

\section{CONCLUSÕES}

Dos 11 casos tratados pelo sôro anti-escarlatinoso, houve duas mortes. Em um dos casos, foi o sôro applicado já no $6 .^{\circ}$ dia de molestia. Aliás o proprio auctor de sôro, como em geral todos os que o tem usado, chamam a attenção para que a sua applicação seja feita o mais cedo possivel devendo ser elle usado até o $4 .^{\circ}$ dia da molestia.

Kling apresenta mesmo, os seguintes resultados:

\begin{tabular}{|c|c|c|c|c|c|c|c|}
\hline Data da inj. & & de $c$ & & & Curas & & Mortes \\
\hline $1 .^{\circ} \mathrm{dia}$ & - & 3 & - & 3 & & - & 0 \\
\hline 2..$^{\circ}$, & - & 32 & - & 30 & $(93,7 \%)$ & - & 2 \\
\hline $3 .^{\circ}$ & - & 90 & - & 80 & $(88,8 \%)$ & - & 10 \\
\hline $4 .^{\circ}$ & - & 73 & - & 57 & $(76,9 \%)$ & - & 16 \\
\hline $5 .^{\circ}$, & - & 22 & - & 13 & $(59,0 \%)$ & - & 9 \\
\hline $6^{\circ} \quad$, & - & 10 & - & 5 & $(5,0 \%)$ & - & 5 \\
\hline
\end{tabular}

Todos os auctores são concordes em dizer que o sôro evita as complicações post-escarlatinosas.

Foi isso, de facto, o que nos foi dado observar.

Quanto á complicações havidas observamos sómente as seguintes:

Nephrite aguda, em 3 casos, $\left(7 .^{\circ}, 8^{\circ}\right.$ e $\left.10^{\circ}\right)$;

Otite ligeira, em um caso, $\left(9 .^{\circ}\right)$;

Abcesso, em dois casos, $\left(9 .^{\circ}\right.$ e $\left.8 .^{\circ}\right)$.

Sobre a descamação, temos a dizer que, em geral, foi ella rapida, em todos os casos. 


\section{BIBLIOGAPHIA}

Dr. Francisco P. Peixoto Sobrinho - Contribuição para o estudo da sôrotherapia especifica da escarlatina. - These inaugural - 1926.

M. Arnold Netter - Emploi du sérum de convalescents et d'anciens malades dans le traitement et da prophylaxie - Clinique e Laboratoire - N. ${ }^{\circ} 1$ - 30 Janeiro - 1926.

Les maladies infectieuses - Actualités - Annales de Laboratoires Clin - Mars - Avril 927 - XXIV Anno - N. 2.

LABORATORIO DE CHIMICA, MICROSCOPIA E BIOLOGIA CLINICAS ANALYSES EM GERAL - VACCINOTHERAPIA

DR. OSCAR M. DE BARROS DR. MENDONÇA CORTEZ

RUA DIREITA, 25 - 1.0 andar

Telephone : Central, 5033

Caixa Postal, 1600

S A O P A U O 